\title{
Bio Fuel Synthesis from Waste Feed Stocks-An Insight
}

\author{
Parkar Saima Munawar, Mulukh Rutuja Santosh, Narhari Gautami Jagdish, \\ Kulkarni Sunil Jayant
}

Department of Chemical Engineering, Gharda Institute of Technology, India

\author{
*Corresponding Author: Parkar Saima Munawar, Department of Chemical Engineering, Gharda \\ Institute of Technology, India
}

\begin{abstract}
Solid waste consists of any unwanted material which is generated by the human activities. Agricultural and domestic(household) wastes are generated in large quantity. These solid wastes can create various problems for the sustainability if proper treatment or disposal is not followed. The solution for reducing the negative impacts of these wastes is $3 R$ 's (Reduce, Reuse \& Recycle). Agricultural waste consists of crop residues (bran, straw, husk, etc.), weed, leaf litter, sawdust, etc. \& domestic waste consist of wastes from household (paper, wood, fruits and vegetables peels, etc.). These wastes can be recycled by using as a raw material for the production of various useful products like biogas, biofuels, composts, etc. Agricultural waste is used as cattle feed and for making compost. Agricultural crop residues which contain lignocellulosic materials like wood, hay, straw, etc. are used for manufacturing bioethanol. Domestic waste is used to produce renewable energy source called as biogas. Recycling of these wastes not only reduces the problem of waste accumulation but also creates high economic benefits. This article gives a brief idea for effective management of agricultural and domestic solid wastes through recycling to produce various useful products.
\end{abstract}

Keywords: Agricultural waste, bioethanol, biogas, domestic waste, lignocellulosic biomass.

\section{INTRODUCTION}

Solid waste generation through various human activities is increasing day by day. A large portion of solid waste contains agricultural and domestic waste. Agricultural waste is increasing rapidly with increase in population as there is hike in the food requirements. Globally, tons of food are wasted from the domestic kitchen and nearly equal amount of waste is also produced. Thus, it is necessary to treat these wastes properly and to use these wastes as a raw material to manufacture the other useful products to reduce the amount of waste generated. These two types of wastes can be utilized to manufacture useful products/energy generation at very low-cost rather than improper disposal [1].

\section{USEFUl Products From DOMESTIC WASTE}

India produces million tonnes of kitchen waste which can be used to produce renewable resource i.e., biogas. By fermenting organic water, biogas is produced which contains methane and carbon dioxide. To avoid choking in the biogas plant due to thick biomass which is unable to microorganisms to digest it, semi-liquid mixture is used for microbial action. A biogas plant is fixed at the Nursery site for disposal of waste generated in canteens of BARC (Bhabha Atomic Research Centre premises) [2]. Thermophiles are used to degrade waste by mixing waste with hot water. Then it undergoes anaerobic degradation by using archaebacteria which produces methane from cellulosic material. Remaining undigested lignocellulosic and hemi cellulosic material are passed to settling tank. High quality of dung is further dug out from settling tank which is used as fertilizer. The gas is generated in the main tank and dome gets lifted up slightly. This gas contains methane, carbon dioxide and water vapours. It burns with blue flame. One precaution should be taken i.e., bones, coconut shells, onion peels should be taken out from the predigester for smoothness of mixer. Kitchen waste can be reduced by fermentation using methanogenic microorganisms, thermophiles, etc. or may reduce biodegradable waste [2].

Local governing bodies collect tonnes of food waste which can be utilized. Food waste can be disposed by landfilling, composting, incineration, etc. but it causes environmental problems like emission of greenhouse gases also contaminates the underground water. Butanol can be produced by 
cellulosic food waste. By fermenting food waste using enzymes butanol is obtained. Acetone-butanolethanol fermentation method is used in glucose based medium. But fermentation process was stopped as they didn't find sufficient increase in ABE concentration and also it was harmful to the culture. They also have done the fermentation in food waste medium in which it is observed that food waste contains a substance which restricts the $\mathrm{ABE}$ production. High concentration indirectly reduces cost required for production of butanol as it reduces energy requirement, water consumption. At high solid concentrations, Simultaneous saccharification fermentation and recovery (SSFR) is used to improve fermentation [3]. In comparison with glucose based medium, food waste medium is better option since more concentration and productivity of ABE has been found in food waste medium. Also, it doesn't require hydrolytic enzymes which is beneficial to economy [3].Now, the production of biobutanol using Clostridia Spp through novel ABE continuous fermentation of selected waste streams (wood hydrolysate, laboratory hand towel and pot ale) and industrial by-products is explained. Wood hydrolysate contains fermentable sugars. Pot ale is the by-product obtained from whiskey production which contains dead yeast cells, yeast residues soluble proteins, soluble nutrients, carbohydrates, etc. Species belonging to the genus Clostridia forms biomass into biobutanol, acetone, butanol, etc. [4]. Reinforced Clostridia Agar (RCA) is the solidified form of Reinforced Clostridia Medium (RCM). After enzymatic hydrolysis, fermentation of wood hydrolysate, laboratory hand towel and pot ale are done in Trypton-yeast extraction acetate medium (TYA) [4]. After continuous fermentation of wood hydrolysate and pot ale, different concentrations of detected solvents are found. By simultaneous saccharification and fermentation of used laboratory hand towel (LHT) using selected solvent producing strains of Clostridia is done. In this way, biobutanol is obtained by acetone-butanol-ethanol fermentation.

Cellulose and soluble sugars like glucose, fructose, and sucrose present in the food waste can be readily converted into ethanol so that household food waste can be used as a raw material. This paper gives an idea about utilizing household food waste (HFW) to produce ethanol. To apply proper enzymatic hydrolysis treatment, calculation of soluble and insoluble sugars, types of polysaccharides is needed. Initially, waste is dried in house dryer and crushed into small particles and then saccharification is done. Using (HPLC) High performance liquid chromatography, ethanol was analysed [5]. Remaining solids were pre-treated hydrothermally. Then solids were removed and solids get dried. Unreacted and pre-treated residue further conducted in a liquefaction reactor. Instead of simultaneous saccharification and fermentation (SSF), Separate Hydrolysis and fermentation gives more ethanol yield [5]. It also increases with addition of catalyst. Hydrothermal pre-treatment in the presence of catalyst was applied. After pre-treatment, catalyst and other inhibitors were separated. At the end of fermentation, remaining waste contains unhydrolyzed cellulose.Due to the presence of cellulose, hemicellulose and starch in food waste, ethanol can be obtained from it. To overcome the problem of cost required for this conversion, on-site production of required enzymes can be done. This paper gives an idea about Bioethanol production from food waste applying the multienzyme system produced on-site by fusarium oxysporum F3 and mixed microbial cultures [6]. This conversion includes pre-treatment which modifies structural characteristics and maximizes sugar and hemicellulose. Enzymatic hydrolysis focuses on structural carbohydrates like starch, cellulose and hemicellulose. Fermentation means metabolism of readily available sugars and further ethanol recovery by distillation. Mixed microbial cultures of $F$. Oxysporum with the yeast of $S$. Cerevisae results in increment of bioethanol productivity than mono-culture of fungus [6].

Recycled waste glass can be used in glass fibreConcrete in replacement with sand. If waste glass is used in concrete, cost will decrease. It will also reduce the landfills. One precaution should be taken while using the glass i.e., if waste glass is used by interacting alkali and silica results in silica gel which may swell and may occur cracks. For preparation of reinforce concrete, cement, sand, dolomite, water, silica fume, glass fibres are more accurate than sand so that it can fill the voids better than sands. In the dry density test, they have concluded that unit weight of concrete with WG is lesser than without WG as silica fume are substituted partially in cement which reduces density of concrete. In the water absorption test, the verification of water absorption with and without WG has been done i.e., WG concrete water absorption is lower than concrete without WG. It is also found that silica fume reduces the water absorption and in the presence of glass fibres, water absorption increases. While studying, they observed increase in compressive strength and tensile strength in the presence of silica fume and glass fibres. Use of WG in concrete in the replacement of sand will protect the natural 
resources and make the concrete industry feasible [7].An idea of use of waste glass powder in the replacement of concrete is given in brief. As manufacturing cement process leads to emission of greenhouse gases, supplementary cementious material (SCM) like silica fume(SF), ground granulated blast furnace slag (GGBS) and fly ash can be used which increases durability, early and long-term strength, workability and economy [8]. This paper examines the potential of glass powder to produce feasible concrete also strength of sample cubes is calculated by crushing and using superplasticizers. As they found some minor differences in the clear and coloured glass, they have used clear glass to compare with mortar. Flow of mortar and concrete having glass powder, their compressive strength, effect of addition of admixture on the compressive strength have been studied in this paper. Use of waste glass in concrete provides remarkable environmental benefits as well as enhances performance of the concrete. If glass powder is added, reduction of cost of cement production up to $14 \%$ is observed [8]. It also reduces greenhouse gas emissions.

Biodiesel is obtained from vegetable oils, yellow grease, used cooking oils or animals which are of long chain fatty acids and esters. Free fatty acid in addition with alcohol gives fatty acid alkyl esters i.e biodiesel which is carried out in mild reaction condition time reduce energy cost and lower waste treatment cost [8]. This paper studies on the effects of reaction parameters like type of enzyme, enzyme amount, type of alcohol, alcohol amount and enzyme reuse required in the production of biodiesel. The enzyme used in the process can be reused by separating it from reaction medium and washing with n-hexane then filtration in vacuum and placing it in a dessicator for 24 hours [9]. The major components of palm oil fatty acid distillate (PFAD) are fatty acids. Biodiesel synthesis from PFAD is carried out with methanol and ethanol. It has been concluded that destabilizing effect of alcohol on lipase decreases with increase in molecular weight [9]. To avoid lipase denaturation caused by high initial concentration of alcohol, they added alcohol stepwise. This paper compares Novozyme 435 and lipozyme RM-IM which is used in esterification reaction. By using smaller amount of alcohol, they found high yield of biodiesel. As Novozym is cheaper than lipozyme RM-IM, it can be used in the synthesis of biodiesel which will lead to economic gains. Type -I collagen is obtained from connective tissues like skin, bones, etc. By using it, acid soluble collagen (ASC) is obtained. Remaining undissolved residue obtained after ASC extraction is used for Pepsin Soluble Collagen (PSC). After extraction, hydrolyzation of extracted collagen is done. Description of collagen in the skin scales and fins of fish (C. catla and C. Mrigala) has been performed using sodium dodecyl sulphate polyacrylamide gel electrophoresis (SDS-PAGE) method. By this method, alpha and beta are the major components found in collagen. Amino acids and disulphide bonds are absent in collagens. Molecular weight of PSC is found slightly lower than ASC. Collagen contains $75 \%$ of protein and remaining is of smaller fragments [10]. Glycine has been found in the skin whereas alanine has been identified in the scales and fins. They found that thermal stability of $C$. Mrigala is higher than $C$. Catla. The collagen can be used in cosmetics, biomedical and pharmaceutical industries [10].

\section{USEFul Products From Agricultural WASte}

Agricultural waste is non product output of production \& processing of agricultural products, whose economical values are less than the cost of collection, transportation \& processing for beneficial use. The conversion of agricultural waste to a useful product that views as a process of generating wealth. To reduce pollution \& waste agricultural waste converted into different forms:

1. Into fuels: we get bio fuels \& biogas from agricultural waste. 140 billion MT of biomass generates every year, globally [11]. Biogas used as a fuel for power plant. It's very economical \&environmentally friendly. Agro waste also applicable for the production of the briquette, soap etc.

2. Into organic manner: agro waste can be converted into compost. It increases crop production.

As population increases need for new alternative fuels has also needed. There are various sources of bioethanol like fermentation of sugar gain from sugarcane molasses, sugar beets. $1^{\text {st }}$ generation biofuels make up by starch crops $\& 2^{\text {nd }}$ generation biofuels which made from lignocellulosic biomass or wooden crops, agricultural waste [12]. It makes harder to extract the required fuel. Resources of lignocellulosic biomass are forest residue, crop residue, waste paper etc. Lignocellulose can be 442 billion per liter of bioethanol [12]. Rice straw is used mainly as a resource to make lignocellulosic biomass within 4 steps we can derive bioethanol from lignocellulosic biomass they are: Preliminary 
Treatment, Hydrolysis, Fermentation, Distillation. By using lignocellulosic material like crop residue, grass, sawdust, woodchips, sludge, livestock manure we get low-cost ethanol. In Canada mainly small-scale plants produces ethanol from agricultural waste IOGE corporation has developed a demo plan for conversion of wood, hay, straw and other agricultural crop residues to ethanol [13]. Bioethanol production from lignocellulosic materials takes three steps

1. To liberate cellulose $\&$ hemicellulose from lignin 2. Depolarization of carbohydrate polymers to produce sugar. 3. Fermentation of mixed hexose and pentose sugars to produce ethanol [13]

Feasibility of generating ethanol from waste materials like crop residues, poultry manure as low-cost lignocellulosic enzyme recycling and use of simultaneous saccharification $\&$ fermentation to integrate ethanol production process. Agricultural waste from sugarcane (its baggage \& bark) \& maize plant (corn husk, corn stalk \& corn cob) was subjected to a pre-treatment process using acid hydrolysis was given to remove lignin because they act as a physical barrier to cellulosic enzymes. Ethanol produced from agro waste by separate hydrolysis \& fermentation. Ethanol production from agricultural waste gain from sugarcane $\&$ maize plants. Steps are to follow to make bioethanol:

1. Raw materials(corn-husk, stalk, cob; sugar cane bark \& bagasse)

2. Cleaning (impurity removal)

3.Oven drying

4. Grating

5. Pre-treatments with acid hydrolysis $》$ lignocellulose removal for sugar exposition

6. Enzymatic, saccharificat, hydrolysis $\left.45^{\circ} \mathrm{C}, 30 \mathrm{~min}\right\rangle$ Termamyl enzymes

7. Fermentation $30^{\circ} \mathrm{C}$ for 5 days $》$ Saccharomyces cereoisiae

8. Filtration (sludge/ flocculate yeast)

9. Alcohol (ethanol) [14].

Conversion of plant residue into biofuels wherein lignocellulose, which form structure of plants consisting of cellulose, hemicellulose \& lignin is first broken down \& hydrolyzed into fermentable sugars, which fermentation from biofuels such as an ethanol [15]. Biofuels derived from starch sugars. Biofuels derived from lignocellulosic biomass like wood, agricultural waste called second generation biofuels. Lignocellulosic biomass is considered as an efficient environmentally friendly it's low-cost alternative.

Composting is the best low-cost alternative solution to overcome waste disposal problem. Composting method degrade all type of organic waste. Vegetable, agro waste, organic waste composition used as crop nutrients, soil additive and for environmental management. Composting process is considered as a most efficient, environmentally friendly \& ergonomically sound, agricultural waste produced from agricultural activities. Mostly Agricultural waste disposal methods harm environment like burning, incineration. We can overcome this by composting dimensions of compost pile was $25^{\circ} \mathrm{C}$ [16]. Composting of rice straws, wheat straws, potato plants, mustard stoves with fish bone bottom was conducted. In the heap Compost box composting conducted for 56 days. From coconut plants also we can make compost. Which are coir pitch and coconut juice. The ratio is 3(coir pitch): 1(rice bran): 0.08(molasses) with manure [16]. Due to metabolic degradation of organic acids \& ammonification process during organic matter. Degradation \& this slowly rejected, because of production of organic acids during biodegradation of lignocellulose in the compost box. Composting of agricultural waste \& with the animal manure can increase the degradation process. Organic waste we can say that the new proposal will cover different groups of fertilizer including organic products like compost. This is beneficial to both humans and environmental interests as it's encourages the recycling of organic waste into nutrients which is used in agriculture. From domestic waste biodegradable materials could be recycled and used as a potential source of plant nutrients instead of being lost through improper disposal [17]. In composting technology effective management approach for recycling \& converting organic waste into useful compost. This technology provides sustainable solution as the produced compost would be used as a fertilizer which improves productivity of soil \& give quality agricultural products. Compost is replacement of inorganic fertilizers. Inorganic fertilizer affects soil composition 
\& other environmental components. Compost application used to restore soil organic carbon \& improves soil aggregation.

Rice husk is a major agricultural waste. By reusing rice husk, we can fabricate magnesium composites by solid state reaction to form Magnesium silicate $(\mathrm{Mg} 2 \mathrm{Si})$ it has high hardness \& young's modulus.

By two processes we can make magnesium composites with the help of rice husk given below:

PROCESS A: Rice husk (cellulose $+\mathrm{SiO} 2$ ) $>$ Biomass power plant (electrical power) $>$ Rice husk ashes $(\mathrm{SiO} 2+$ remained Carbon) $>\mathrm{Mg}$ composites alloys with $\mathrm{Mg} 2 \mathrm{Si}$ augmentation.

PROCESS B: Fermentation process $>$ biomass ethanol and methanol $>$ Rice husk ashes $(\mathrm{SiO} 2$ and very few organics) $>\mathrm{Mg}$ composites alloys with $\mathrm{Mg} 2 \mathrm{Si}$ augmentation [18].More than $620 \mathrm{MT}$ of agricultural waste generated annually in India, from this only $25-30 \%$ waste is get utilized as livestock fodder and energy production implementation of effective agricultural waste management provide better inputs to crop weeds and crop residue as a cattle feed, dung from cattle is input for biogas production, \& biogas is input of vermicompost which is useful for betterment of crop (Management\& handbook, 2011) [19]. Waste gains are utilized as a poultry feed. Crop residue utilize for mulching (organic matter) it reduces water requirement \& weed epidemic. Integrated agricultural waste management is beneficial in many ways so it improves soil health \& soil fertility, it solves energy crisis, insignificant use of harmful chemical fertilizers.Agricultural waste is used as a feedstock for several products like energy production, dye adsorption. From food waste also we can make useful products, according to study conducted by Nagle (2011) fruit residues have high energy content [20]. According to Faraco (2011) we get lignocellulosic waste from cereal crops, tomatoes, olive trees \& grapes in a large amount \& that lignocellulosic material used as a raw material for ethanol production [20].

Resources of biomass are agricultural and forest residues. Biomass is considered as a renewable energy resource with high potential energy. Biomass used to solve global problems like fossil fuels and global warming and used in electricity and power generating. Bioethanol is also made by fermentation of sugar with the help of biomass (made by starchy crops) and also by lignocellulosic biomass [21]. By two reactions biomass get converted into bioethanol

1. Hydrolysis Reaction: this reaction converts polysaccharides into raw materials to sugar. In this reaction acids and enzymes are used as a catalyst.

2. Fermentation: it converts sugar to ethanol. This reaction occurs with the help of yeast.

$$
\text { Glucose----- } \rightarrow \text { Ethanol + Carbon dioxide [21] }
$$

For performing alcoholic fermentation, needs to adapt the technology to achieve the residual thermal energy it also valurize agricultural waste. We get Saccharomyces bayanus as starter yeast from waste fruits (apples, kiwifruit, peacheswaste, corn threshing residue) [22].For alcoholic fermentation agricultural waste requires for example sugar crops, starchy crops, cellulosic crops etc. After the pretreatment on this crop's fermentation occurs. [23]. Now climate changes \& increases of anthropogenic GHG emissions, environmental sustainability of agricultural systems may be increases with increasing C- based input used efficient [23].India is the second largest country in the agro based economy with year-round crop cultivation, it generates large amounts of Agro waste which includes crop residue. Agricultural waste sector should study the examples from other waste management where collection, segregation, recycling \& disposal are institutionalized to source. In agriculture after harvesting process crop residue (e.g., stalks, stubble, stems, leaves \& seed pods) remain on the field which is useful usable resources. Also, sugarcane bagasse and molasses are lignin is a resistance to fermentation process (very resistant to chemical and biological process). Rice, wheat, sugarcane have lignocellulosic biomass. Lignocellulosic biomass composed of cellulose, hemicellulose, lignin is valuable due to its major availability as a raw material for the production of biofuels. Biodegradation of agricultural waste effectively carried out by anaerobic \& aerobic process. Anaerobic digester can convert biomass into biogas its renewable energy source contains $50 \%$ of methane and solid residue is usable as a \& Potential Solution Int.J. Environ.Res. Public Wealth,2019,16,832 fertilize nutrients [24]. 
Reuse of agricultural residual waste strengthens biological properties of soil in the form of compost. The conversion of agricultural residual waste into raw compost this conversion is followed by defensive wall (fortification) decomposer microorganisms to produce quality compost products. Limitless chemical fertilizer use has adversely affected soil biodiversity. Reuse and recycling of agro wastes as an organic input to increase soil productivity. Crop residue is a source of organic carbon. Agricultural residue contains $20-30 \%$ of lignin - hemicellulose it has potential biotechnological values. Role of microorganisms as bioconversion agents is important, they have fast ability to convert cellulosic \& lignocellulosic wastes to organic manner.

Following steps followed to get value added products from agro wastes:

Farm waste (Residue) >conversion to raw compost > Quality scale up with decomposer microorganisms (30-35 days) bio-organic farm input > Fortified bio-organic farm inputs > Microb enriched products (pot mix compost) > Enterprising- pot mix for gardening, biofertilizer for soil, inoculant mixture, soil conditioners $>$ for sale.

\section{CONCLuSion}

Recycling of agricultural and domestic waste can give useful products which are low cost. It helps in reducing the waste accumulation and is a best alternative to improper disposal.

\section{ACKNOWLEDGEMENTS}

The authors are thankful to the institute for the cooperation.

\section{REFERENCES}

[1] Eriksen N. G., Coale F. J., Bollero G. A., Soil Nitrogen Dynamics and Maize Production in Municipal SolidWaste Amended Soil, 91(6), 1999, 1009-1016.

[2] S. P. Kale and S. T. Mehetre, Biogas plant based on kitchen waste, 2020.

[3] Haibo H., Vijay S. and Nasib Q., Butanol production from food waste: a novel process for producing sustainable energy and reducing environmental pollution, 2015.

[4] Chinedu C. E., Abdrazaq O. I., Ftepti B. J., Adamu A. R., Ogechukwu J. E., Igwe V., Production of biobutanol using Clostridia Spp through novel ABE continuous fermentation of selected waste streams and industrial by-products, 2021.

[5] Leonidas M., Dimitris K.,Maria L. and Paul C., Utilization of household food waste for the production of ethanol at high dry material content, 2014.

[6] George P., Aggelos G., Aikaterini K., Styliani K., Dimitris K., Bioethanol Production from Food Waste Applying the Multienzyme System Produced On-Site by Fusarium oxysporum F3 and Mixed Microbial Cultures.

[7] K.I.M. Ibrahim, Recycled Waste Glass as A Partial Replacement Of sand in glass fibre reinforce Concrete, 2020.

[8] G. M. Sadiqul Islam, M. H. Rahman, N. Kazi, Waste glass powder as partial replacement of cement for sustainable concrete practice, 2016.

[9] Igor Nascentes dos Santos Correa, Susana Lorena de Souza, Marly Catran, Otavio Luiz Bernardes, Marcio Figueiredo Portilho, and Marta Antunes Pereira Langone, Enzymatic Biodiesel Synthesis Using a Byproduct Obtained from Palm Oil Refining, 2011.

[10] Shahid Mahboob, Isolation and characterization of collagen from fish waste material- skin, scales and fins of Catla catla and Cirrhinus mrigala, 2015.

[11] Km. Sheetal Banga, Sunil Kumar Agricultural Waste to Wealth ISSN 2581-8317 Volume 1-Issue 10October 2019.

[12] Yug Saraswat, Nikita Chokshi Bioethanol from Agricultural Waste August 2014.

[13] Pascale Champagne Bioethanol from Agricultural Waste Residue Environmental Process (vol 27, No. 1) DOI 10.10002/ep.

[14] W.Braided, L.A.Kanu, U.S.Oranusi, S.A. Adeleye Production of Bioethanol from Agricultural Waste Journal of Fundamental \& Applied Science ISSN 1112-9817.

[15] Venkatesh Chaturvedi Pradeep Kumar an Overview of key Pretreatment Processes Employed for Bio Conversion of Lignocellulosic biomass into Biofuels \&Value-Added Products.

[16] Aeslina Abdul Kadir Nur Wahidah Azhari Siti Norati Fah Jamaludin an Overview of Organic Waste in Composting Icon.CEES 2015. 
[17] Tahseen Sayara, Rezq Basheer Salimia, Fatima Hawamade, Antoni Sanchez Recycling of organic waste through Composting Process performance \& Compost Application in Agriculture Agronomy 2020, 10,1838 .

[18] Katsuyoshi Kondah, Hindeki Oginuma, Junko Umeda, Takateru Umeda Innovative Reuse of Agricultural Wastes as an Industrial Raw Materials to form Magnesium Composites Materials Transaction, volume 46 No. 12 (2005) pp. 2586 to 2591.

[19] Vivek Kumar Patel, Abhay Kumar, Ankit Singh, Kumar Anshuman Integrated Agricultural Waste Management: A Solution of many problems Food \& Scientific Reports ISSN 2582-5432.

[20] Evan Graeme Rees Davies, Yang Liu Agricultural Wastes Water Environment Research, Volume 84, Number 10.

[21] A.B.M.S.Hossain, A.A.Saleh, S.Aishah, A.N.Boyce,P.P. Chowdhury, M.Naqiuddin Bioethanol Production from Agricultural Waste Biomass as Renewable Bioenergy Resource in Biomaterials IFMBE Proceedings Vol. 21.

[22] Raffaele Cutzu, Laura Bardi Production of Bioethanol from Agricultural Waste Using Residual Thermal Energy of a cogeneration Plant in the Distillation Phase, Fermentation 2017,3,24;doi:10.3390/ fermentation 302002.

[23] Mariangela Diacono, Alessandro Persian, Elena Testani, Francesco Montemurro, Corrado Liaccia Recycling Agricultural Waste \& By Products in Organic Farming Biofertilizer Production, Field Performance \&Carbon Footprint Analysis Sustainability 2019, 11, 3824.

[24] S. Bhuvneshwari Hiroshan Hettiorach chi Jay N. Meegoda Crop Residue Burning in India: Policy Challenges.

[25] Dhananjaya P. Singh, Ratna Prabha, Shukla Renu, Pramod Kumar Sahu, Vivek Singh International Journal of Recycling of Organic Waste in Agriculture (2019) 8 (suppl) S457- S472.

Citation: Parkar Saima Munawar et al." Bio Fuel Synthesis from Waste Feed Stocks-An Insight", International Journal of Advanced Research in Chemical Science (IJARCS), vol. 8, no.1, pp. 35-41, 2021. http://dx.doi.org/ 10.20431/2455-7153.0801005

Copyright: (C) 2021 Authors. This is an open-access article distributed under the terms of the Creative Commons Attribution License, which permits unrestricted use, distribution, and reproduction in any medium, provided the original author and source are credited. 